\title{
Long-Term Coexistence of Two Invasive Vespid Wasps in NW Patagonia (Argentina)
} \author{
9888-4470

\section{Maité Masciocchi} \\ CONICET Patagonia Norte \\ Juan Carlos Corley \\ CONICET Patagonia Norte
}

Ana Julia Pereira ( $\square$ anajulia_86@yahoo.com.ar)

CONICET: Consejo Nacional de Investigaciones Cientificas y Tecnicas https://orcid.org/0000-0001-

\section{Research Article}

Keywords: Vespula germanica, Vespula vulgaris, biotic resistance, biological invasion, Lotka-Volterr

Posted Date: November 29th, 2021

DOI: https://doi.org/10.21203/rs.3.rs-1020520/v1

License: (9) This work is licensed under a Creative Commons Attribution 4.0 International License. Read Full License 
1 Title: Long-term coexistence of two invasive vespid wasps in NW Patagonia (Argentina) ${ }^{1}$

2

$3 \quad *$ Ana Julia Pereira ${ }^{1}$

4 Maite Masciocchi ${ }^{2}$

5 Juan C. Corley ${ }^{2,3}$

6

$7 \quad{ }^{1}$ Centro de Investigaciones en Toxicología Ambiental y Agrobiotecnología del Comahue, CITAAC

8 (CONICET, UNCo), Neuquén, Argentina.

9 '2Grupo de Ecología de Poblaciones de Insectos, IFAB (CONICET, INTA EEA Bariloche),

10 Bariloche Argentina.

$11{ }^{3}$ Departamento de Ecología, Centro Regional Universitario Bariloche, Universidad Nacional del 12 Comahue, Bariloche, Argentina.

$13{ }^{*}$ corresponding author: pereira.ana@conicet.gov.ar

14 ORCID:

15 Ana Julia Pereira: 0000-0001-9888-4470

16 Maité Masciocchi: 0000-0002-0095-2170

17 Juan C. Corley: 0000-0002-8032-2223

18

19 Running head: coexistence between two exotic social wasps

20

21 Community ecology - original research

${ }^{1}$ Authors' contributions AJP, MM and JJC conceived the idea; AJP and MM collected the data; AJP analyzed the data and developed the mathematical models; all authors were involved in writing the manuscript. 


\section{Abstract}

23 In Patagonia (Argentina) two non-native vespid wasps became established in the last decades.

24 Vespula germanica was first detected in 1980 while $V$. vulgaris arrived some 30 years later. Both 25 species can have a strong negative impact on agriculture, natural environment and on outdoor 26 human activities. Invasion success -the establishment and spread of a species- may be influ27 enced negatively by the degree of interaction with the resident native community, and alien 28 species already present. The sequential arrival of these two wasps allows us to understand key 29 questions of invasion ecology. Additionally, recognizing the outcome of the invasion by vespids 30 in Patagonia -a region lacking native social wasps-, may help plan species-focused mitigation 31 and control strategies. We explored long term species coexistence through the deterministic 32 Lotka-Volterra competition model, using site-specific field data on prey captured (to estimate 33 niche overlap) and current nest densities in sites. Food items carried by workers were similar but 34 there is some degree of segregation. V. germanica nest density in shared sites, and in sites 35 without coexistence, were 3.14 and 3.5 respectively, being higher for $V$. vulgaris with 4.71 and 36 5.33. The model predicts stable co-existence of both species in the invaded range, yet a higher 37 abundance of $V$. vulgaris should be expected. Added to evidence on other foraging behavioral 38 attributes of both wasp species and the invasion patterns observed in other regions, it is likely 39 that the prior presence of $V$. germanica does not contribute significantly to the biotic resistance 40 of the invaded range for $V$. vulgaris.

41 Keywords: Vespula germanica, Vespula vulgaris, biotic resistance, biological invasion, Lotka42 Volterra 
44 Competition is considered as one of the major forces responsible for shaping the distribution of 45 species in space and time (Tilman 1982; Connor and Simberloff 1983; Begon et al. 2006). For 46 more than a century, questions about species competition remain to fascinate researchers. This 47 is largely because understanding competition can help, not only understand how species in 48 communities are organized, but also address management problems including the conservation 49 of rare species (DeCesare et al. 2010), forecasting climate change impacts (Chu et al. 2016) 50 and the control of biological invasions (MacDougall et al. 2009).

51 It is widely accepted that competition plays a key role in any invasion process (Mack et al. 2000;

52 Vilà et al. 2011; Pyšek et al. 2012). Competitive interactions can contribute to biotic resistance 53 the reduction of invasion success- as it may hinder the establishment and spread of an invasive 54 species in the new environment. In general, it is claimed that the presence of resident 55 competitors in the arrival area my affect invasion of new species by reducing their access to 56 resources due to exploitation or interference. Competition then, may negatively affect 57 reproduction and population growth rates of non-native species in the new areas (Davis 2009).

58 However, biotic resistance does not only occur between native and an invasive species. 59 Competitive interactions have been observed between naturalized exotic species, and new alien 60 species (Simberloff and Von Holle 1999). For example, it has been shown that Linepithema 61 humile, an invasive ant native to South America, competes with other species in the invaded 62 range (i.e., California, USA), reducing foraging success and survival, as well as the 63 establishment of new ant colonies (Holway and Case 2001; Kabashima et al. 2007). According 64 to the principle of competitive exclusion, the coexistence of two species is not possible if they 65 compete for at least one resource that is limiting for both, so that the "stronger" competitor tends 
to eliminate the "weaker" species by competition (Gause 1934; Begon et al. 2006). However, if

67 resources are not limiting as may often occur in invaded areas, arriving species may also be

68 negatively affected by resident natives or non-native competitors, if the efficiency in resource 69 exploitation is different, and best foods are monopolized by the best competitor (Masciocchi et 70 al. 2010).

71 In nature, the existence of competitive interactions is still hard to assess as for most 72 communities modeled by competition, this maybe have occurred in some past time (Connell 73 1980). However, competition may be inferred through an understanding of species behaviors 74 and the identification of overlapped niche requirements, such as similar feeding habits (Grangier 75 and Lester 2012; Pereira et al. 2013). Else, the performance of exclusion experiments (Fox et al. 76 1985) or the use of mathematical modeling may allow us to infer the existence and 77 consequences of competition (Kaplan et al. 2010; Vet et al. 2018).

78 The "Lotka-Volterra Model" is a remarkable example of a simple equation system approach to resource competition elaborated by Albert Lotka and Vito Volterra in the 1920's (Wangersky 1978). This classical approach has been generalized to multiple species engaging in all types of 81 ecological interactions (Solé and Bascompte 2012). The generalized simple Lotka-Volterra 82 equation is frequently employed to model communities due to its ease of parameterization and 83 well-established mathematical properties (Gamarra et al. 2005; Warren et al. 2019). Theory 84 supporting the Lotka-Volterra model rests on the assumption that species interactions play a 85 major role in structuring a community. According to Wilson et al. (2003), taking a mean-field 86 approximation of those interactions across the community enables us to calculate a distribution 87 of target species densities that determines, to a large degree, the temporal development of the 88 ecological community, including the success of biological invasions. 
89 Several species of social wasps (Hymenoptera: Vespidae) have shown to be remarkably 90 successful invaders of new territories around the world (Spradbery and Richards 1973; 91 Clapperton et al. 1989; Wilson and Holway 2010; Masciocchi and Corley 2013; Lester and 92 Beggs 2019). In the last decades, two of the most notorious species, Vespula germanica and $V$. 93 vulgaris, have invaded Australia, New Zealand and South America, rapidly becoming very 94 common insects within the new range (Beggs et al. 2011). In the 1980's the region known as 95 Patagonia (Southern Argentina) was invaded by V. germanica (Fabricius; Hymenoptera) and 96 some 30 years later V. vulgaris (Linnaeus; Hymenoptera) was first detected (Willink 1980; 97 Masciocchi et al. 2010). Both species of Vespidae are native to Europe and North Africa and co98 exist in large parts of their native range (Delmotte and Marchal 1982; Dvorak and Landolt 2006).

99 Throughout the invaded range, however, both these wasps are recognized as having strong 100 negative impact on agro-industrial economic activities, the natural environment and outdoor 101 human events, due to their venomous sting, aggressive behavior and efficient, opportunistic 102 foraging abilities (Clapperton 1989; Yeruham et al. 2002; Beggs et al. 2011; Maclntyre and 103 Hellstrom 2015).

104 Sequential invasion by these two eusocial wasps has been observed also elsewhere. In New 105 Zealand, for example, V. germanica first arrived in 1945 and since spread widely throughout the 106 country, but 30 years later, V. vulgaris arrived and displaced it from many environments 107 (Sandlant and Moller 1989; Harris et al. 1991). Both species are defined as opportunistic 108 predators and scavengers, with food preferences affected by the development of their colonies 109 and the availability of the environment (Akre and MacDonald 1986; Barr et al. 1996; Spurr 1995; 110 Pereira et al. 2013). Even though both species are seen as generalists, their diet and phenology 111 are very similar, suggesting an overlap in food preferences and foraging behavior (mainly 112 protein-rich foods) towards the end of summer and autumn when colonies need to feed future 113 reproductive individuals (gynes and males; Sackmann et al. 2000). Moreover, feeding activities 
114 observed for both wasp species may be disrupted by each other's presence, suggesting that

115 these two species could interfere between each other (Masciocchi et al. 2019). It has been

116 suggested that differences in the foraging strategies displayed by these wasps may render $V$.

117 vulgaris with a competitive advantage over V. germanica in certain scenarios (Harris et al. 1994;

118 Pereira et al. 2016). Given that there is no evidence of regions invaded only by $V$. vulgaris or of

119 an invasion sequence led by $V$. vulgaris, the role played by either species on the invasion

120 process of the other remains unknown, with strong practical implications.

121 The recent invasion of $V$. germanica and $V$. vulgaris in NW Patagonia offers a unique opportunity

122 to study a variety of ecological and applied questions regarding the future of these species in

123 terms of invasion success of each species and their geographical spread. In this study, we

124 explore the potential role played by $V$. germanica on the invasion process of $V$. vulgaris wasps in

125 Patagonia, using the classical Lotka-Volterra model. Based on the similarities in foraging habits

126 and diets between both species, our hypothesis is that the presence of $V$. germanica, prior to the

127 arrival of $V$. vulgaris, adds biotic resistance, affecting the final outcomes of the invasion process.

\section{Materials and Methods}

129 Study sites and field experiments

130 The study was carried out under natural conditions in scrubland areas, within the Nahuel Huapi

131 National Park, Patagonia, Argentina $\left(41^{\circ} \mathrm{S}, 72^{\circ} \mathrm{W}\right)$. This area, located close to the city of

132 Bariloche, is defined as an appropriate habitat for both wasps (e.g., a disturbed, tree-less zone,

133 with an annual rainfall of ca. $800 \mathrm{~mm}$, mostly concentrated during the winter months). The most

134 characteristic plant species that describes the area is the native bamboo Chusquea culeou, and

135 woody shrubs Embothrium coccineum and Fuchsia magellanica. Other species of the genus

136 Berberis are also present. All assays were carried out in different sites where both Vespula 
137 species are known to be abundant. Experiments were conducted during March of 2014, on

138 sunny days with no wind, between 10 AM and 5 PM, to minimize the effects of weather (i.e., 139 daily temperatures) on wasp activity.

140 We selected 12 sites of ca. 1 ha and in each, 10 transects were established (each located $10 \mathrm{~m}$ 141 a part from another) where we searched for all wasp nests. Each nest found was marked, geo142 referenced and the species was identified. Nest density was chosen as an estimator of wasp 143 abundance (Archer 1985, 2001; Barlow et al. 2002; Estay and Lima 2010). To estimate niche 144 overlap between $V$. germanica and $V$. vulgaris, we selected 10 of the marked nests for each 145 species. Using an entrance trap to catch returning foragers (adapted from Harris and Oliver 146 1993; Fig. 1), we captured, counted, and classified all prey collected by foragers returning to 147 their nests. Traps were placed at the entrance of each nest (simultaneously, to avoid differences 148 related to sampling times) causing a minimal disturbance to the colonies, and we ensured 149 foragers did not establish alternative entrances. After 10 minutes of placing, the inner part of the 150 trap was removed, and trapped foragers were anesthetized with $\mathrm{CO}_{2}$. The assay was repeated 151 twice for each nest with a difference of two days. Prey items were identified with a digital 152 magnifying glass to $40 X$ level and the help of specialists.

153 To assess the existence of competitive interactions (i.e., to determine the dietary overlap)

154 between $V$. germanica and $V$. vulgaris, we ran the Lotka-Volterra model for interspecific 155 competition (Volterra 1926; Lotka 1932; Takeuchi 1996; Neal 2004; Momo and Capurro 2006). 156 This model, may be written with an explicit intraspecific competition coefficient as a set of 157 coupled equations:

$$
V . \text { germanica } \frac{d N_{V G}}{d t}=r_{1} N_{V G}\left(1-\frac{N_{V G}+\alpha N_{V V}}{K_{1}}\right)
$$




$$
V . \text { vulgaris } \frac{d N_{V V}}{d t}=r_{2} N_{V V}\left(1-\frac{N_{V V}+\beta N_{V G}}{K_{2}}\right)
$$

160 where $N_{V G}$ represents the size of $V$. germanica population, measured as nest density (nest/ha),

$161 r_{1}$ is its intrinsic growth rate, $K_{1}$ is maximum population density in the study area (i.e., the

162 carrying capacity) and $\alpha$ is the competition coefficient. A similar equation is written for $V$. vulgaris,

163 indicated by the subindex $V V$. The competition coefficients $\alpha$ and $\beta$ represent the reduction in

164 growth of one species caused by each additional individual of the other (Momo and Capurro

165 2006). Therefore, the term $\alpha N_{V G}$ represents the effects of $V$. vulgaris on $V$. germanica populations

166 and $\beta N_{v v}$ represents the effects of $V$. germanica on $V$. vulgaris.

167 The values of $N_{v G}, N_{v v}, K_{1}$ and $K_{2}$ were obtained from the number of nests of each species in the 168 sites where they coexisted $(N)$ and, from sites where each species was found by itself, we 169 estimated $K$. We assumed that the intrinsic growth rates were similar for both wasp species 170 (Moller 1991; Donovan et al. 1992; Leathwick 1997; Leathwick et al. 1999).

171 The competition coefficients were calculated from the asymmetric index of niche overlap of 172 MacArthur and Levin (1967) as:

$$
M_{j k}=\frac{\sum_{i}^{n} \text { pij.pik }}{\sum_{i}^{k} p^{2} j} \quad M_{k j}=\frac{\sum_{i}^{n} \text { pij.pik }}{\sum_{i}^{k} p^{2} k}
$$

174 where $p_{i j}$ and $p_{i k}$ are the proportions of resource $i$ used by species $j$ and $k$. This index is 175 asymmetric and allows obtaining a competition coefficient for each species. 
176 To determine the equilibrium abundance of $V$. germanica and $V$. vulgaris populations (i.e., the

177 intersection of the zero isocline), we did a phase diagram, and the isoclines were analyzed

178 (Edelstein-Keshet 1988; May and McLean 2007). Both species of Vespula will be in equilibrium

179 when:

$180 \frac{d N_{V G}}{d t}=0 y \frac{d N_{V V}}{d t}=0$

181 this occurs when populations stop growing. In this case, the equations are:

182

$N_{V G}=K_{V G}-\alpha N_{V V}$ y $N_{V V}=K_{V V}-\beta N_{V G}$

183 These two equations define two lines called zero-growth isoclines.

184 Statistical analysis

185 The non-parametric Kruskal Wallis test was used to compare the type of prey carried by $V$. 186 germanica and $\mathrm{V}$. vulgaris foragers. Analyses were performed using the $\mathrm{R}$ statistical 187 environment (R Core Team 2020). Lotka-Volterra models and phase diagrams were run and 188 plotted with deSolve (Soetaert et al. 2010) and ggplot2 packages of R statistical environment 189 (Wickham 2016).

\section{Results}

191 V. germanica and V. vulgaris diets

192 A total of 2022 V. germanica foragers were trapped at the nest entrance, of which $245(12 \%)$ 193 entered with prey. Of the total prey items recovered, $78 \%$ were insects and the rest were 
194 remains that could not be identified. For V. vulgaris, a total of 1936 workers were captured, of 195 which $202(10.4 \%)$ carried prey. Of these, the majority (89\%) were insects. Regarding the 196 composition of the diet, there are differences between some types of prey that $V$. germanica and

197 V. vulgaris brought to their nests (Kruskal-Wallis test, $\mathrm{P}<0.05$; Fig. 2). The prey identified for $V$. 198 germanica were, for the large part, insects belonging to the Diptera (36\%) and Orthoptera (18\%) 199 orders. On the other hand, Hemiptera (35\%) and Coleoptera (19\%) were the predominant orders 200 in the diet of $V$. vulgaris.

\section{Competitive interaction models}

202 The competition coefficient for V. germanica, calculated using the MacArthur and Levins' 203 asymmetric index, was 0.53 . The number of nests per hectare in coexistence sites, and in sites 204 where each species was found by itself, were $N_{1}=3.14$ and $K_{1}=3.5$ respectively. On the other 205 hand, the coefficient of competition for $V$. vulgaris was 0.54 , with $N_{2}=4.71$ and $K_{2}=5.33$. With 206 these data, the population growth dynamics of both species was modeled (Fig. 3).

207 According to the model, populations of $V$. vulgaris grew exponentially until they reached 208 densities of 4.83 nests/ha, at which point they would remain at a stable equilibrium. However, 209 populations of $V$. germanica grew to a maximum density of 1.65 nests/ha but then declined to 210 equilibrium values of 0.85 nests/ha, in approximately 20 year-long simulations (Fig. 3).

211 The phase diagram showed that isoclines intersect at positive densities for both species $(x=0.85$, $212 y=4.83$; Fig. 4). Since both $\alpha$ and $\beta$ take values less than one, the following inequalities are 213 obtained: (1) $K_{1}<K_{2} / \beta$ and (2) $K_{2}<K_{1} / \alpha$. Therefore, the carrying capacity of each species is less 214 than the equivalent in individuals of the other species, suggesting that intraspecific competition 215 overmatches competition among both species. 
217 Vespula germanica and V. vulgaris are both truly social wasps that are successful invaders

218 found in the same regions in different parts of the world. This, added to the fact that they often

219 become remarkably common insects in the invaded range and are considered pests, has made

220 the the center of considerable research attention (e.g., Akre and MacDonald 1986; Bashford

221 2001; Beggs et al. 2011; Buteler et al. 2021). Both wasps share common morphological and

222 behavioral aspects and are often found together in similar habitats, outside their native range.

223 Here we show, by means of a simple phenomenological model fed on field collected data that,

224 for the NW Patagonia conditions, co-existence is the most likely long-term outcome in which $V$.

225 vulgaris will be the most common species, despite the fact that it arrived three decades later.

226 Knowledge about biology and ecology of pest species is important to manage invasive social 227 wasps. Current control methods for Vespula wasps are directed towards the destruction of nests 228 and the application of toxic baits, however their success is often variable and poses a risk for 229 non-target species. Next-generation pest control technologies, including synthetic lures, have 230 been proposed as part of an alternative solution (Mascioccchi et al. 2019). Based on our co231 existence results, future management strategies suggest that local site studies on the 232 preponderance of a given Vespula spp., may be needed, to focus species-specific practices. 233 Since the population density of $V$. vulgaris is expected to be 5 times greater than that of $V$. 234 germanica, studies on the impact and habits of the former are warranted.

235 Our results also show that, in general, the diet of these wasps was similar, however preys 236 collected were different. V. germanica foraged, mostly, on insects belonging to Diptera and 237 Orthoptera orders. In contrast, $V$. vulgaris had a diet composed for the most part of insects of 238 Hemiptera and Coleoptera orders. In Chile, Mangunacelaya et al. (1986) found that the most 
consumed orders by V. germanica are Araneae, Lepidoptera and Diptera. In New Zealand, diets

240 of both species were compared noting that Diptera was the most abundant prey component for

241 both V. germanica and V. vulgaris. However, some differentiation was observed, with $V$.

242 germanica foraging more Diptera and less Araneae, Hemiptera and Lepidoptera than V. vulgaris

243 (Harris and Oliver 1993). Undoubtedly, exact proportions will vary at each site, depending on the

244 local abundance of prey, reflecting the opportunistic behavior of both species. However, the 245 observed differences could suggest that $V$. vulgaris and V. germanica present a prey partitioned 246 consumption behavior that could potentially lead to reduction in niche overlap. According to 247 Harris (1991), V. germanica foragers return to nests with heavier prey loads than V. vulgaris, 248 making in comparison, fewer trips. However, the higher foraging efficiency reported for $V$. 249 vulgaris does not seem to have a significant effect in Patagonia. Our results suggest the 250 coexistence of both species. Future studies could evaluate these characteristics to determine 251 the magnitude of these variables.

252 Given their similarity in biology, and overlap in nesting sites and diet, these species may have 253 developed strategies to avoid or reduce competition. In New Zealand and Patagonia, it has been 254 noted that both species have spatial resource partitioning, where $V$. vulgaris were found foraging 255 in the shrubland, mid height level while $V$. germanica were more commonly seen foraging at the 256 ground level (Harris et al. 1991; Masciocchi et al. 2019). In line with this, Pereira et al. (2016) 257 found that V. germanica significantly avoids V. vulgaris visual and odour cues in bioassays with 258 free-flying wasps arriving to protein baits. Together these findings suggest that interspecific 259 competition may not determine the interactions among both wasps and could explain co260 existence as the most likely long-term outcome.

261 In regards of the invasion process described for these social wasps, it is likely that intraspecific 262 competition plays a role. Pusceddu et al. (2018) showed that social facilitation, given by local 
263 enhancement, promoted agonistic competition between Vespula wasps, suggesting that 264 individuals from different colonies, that find themselves at the same foraging site, will defend 265 their own prey item from other conspecifics. Competitive interactions between individuals of $V$. 266 germanica during feeding, even when the food resource is not scarce, also have been described 267 by Parrish and Fowler (1983). This evidence suggest that no invasion meltdown process occurs 268 among these very similar vespids, but instead a quota of biotic resistance is added to $V$. vulgaris 269 invasion by the prior arrival of the competing species, V. germanica. Unfortunately, all reported 270 invasions by both these wasps have occurred in a similar sequence, so we cannot ascertain 271 whether $V$. vulgaris' invasion could mitigate the establishment of $V$. germanica, although this is 272 also a site-dependent process as both species are generalists and opportunistic.

273 Models of resource competition play an important role in ecology. Lotka-Volterra 274 phenomenological model allows us to understand if and by how much, species affect each other 275 without knowing the mechanism behind that interaction (Looijen 1998). It is a good simple model 276 to introduce a first approximation into the study of species interactions, however it has been 277 highly criticized for its simplicity. Still, several studies had used this model to successfully 278 analyze interactions between species recently (Carusela et al. 2009; Torre et al. 2017; 279 Chalmandrier et al. 2021; Deng et al. 2021; Tamura et al. 2021). Fort (2018) concluded that the 280 Lotka-Volterra model is a useful quantitative tool for describing the equilibrium species 281 abundances and make accurate predictions.

282 Understanding the interplay between invasive species and invasion process, is a key issue 283 related to their invasion ecology (e.g., biological meltdown, biotic resistance), population 284 outcomes and species-specific management. Our study is a first step to document the 285 interaction between $V$. germanica and $V$. vulgaris in Argentine and provides an additional 286 example of the use of Lotka-Volterra modelling approach. We provided information, with field 
287 data, indicating that the coexistence of both species of wasps is likely in Patagonia. In turn, we

288 suggested that the preference for different preys and intraspecific competition could be a 289 plausible explanation to the coexistence observed in Argentina. Improving our understanding of 290 the interaction between invasive species may help to develop appropriate techniques for 291 managing undesired invasive social wasp populations.

292 Acknowledgements: We are especially grateful to Santiago Aisen for help with prey species 293 identification. Fernando Momo provided useful comments and mathematical advice during 294 model development

295 Declarations

296 Funding This study was funded by a grant from CONICET (Consejo Nacional de 297 Investigaciones Científicas y Técnicas, PIP 2010, Grant \#11220090100043) to Juan C. Corley

298 Conflicts of interest The authors declare that they have no conflict of interest

299 Ethics approval Not applicable

300 Consent to participate Not applicable

301 Consent for publication Not applicable

302 Availability of data and material All raw data is sorted at digital Institutional Repository of INTA 303 (Instituto Nacional de Tecnología Agropecuaria), through the link 304 http://hdl.handle.net/20.500.12123/10582, and access will be unrestricted upon acceptance

\section{Code availability Not applicable}


Authors' contributions AJP, MM and JJC conceived the idea; AJP and MM collected the data;

AJP analyzed the data and developed the mathematical models; all authors were involved in writing the manuscript.

309

310

311

312

313

314

315

316

\section{References}

Akre RD, MacDonald JF (1986) Biology, economic importance and control of yellowjackets. Economic impact and control of social insect. In: Bradleigh Vinson S (ed.) Economic Impact and Control of Social Insects. Pergamon Press, New York, pp 353-412

Archer ME (1985) Population dynamics of the social wasps Vespula vulgaris and Vespula germanica in England. J Anim Ecol 54:473-85

Archer ME (2001) Changes in abundance of Vespula germanica and V. vulgaris in England. Ecol Entomol 26:1-7

Barlow ND, Beggs JR, Barron MC (2002). Dynamics of common wasps in New Zealand beech forests: a model with density dependence and weather. J Anim Ecol 71: 663-671

Barr K, Moller H, Christmas E, Lyver P, Beggs J (1996) Impacts of introduced common wasps (Vespula vulgaris) on experimentally placed mealworms in a New Zealand beech forest. Oecologia 105:266-270

Bashford R (2001) The spread and impact of the introduced vespine wasps Vespula germanica (F.) and Vespula vulgaris (L.)(Hymenoptera: Vespidae: Vespinae) in Tasmania. Aust Entomol 28:1-12

Beggs JR, Brockerhoff EG, Corley JC, Kenis M, Masciocchi M et al (2011) Ecological effects and management of invasive alien Vespidae. BioControl 56:505-526

Begon M, Townsend CR, Harper JL (2006) Ecology: from individuals to ecosystems, 4th edn. John Wiley \& Sons, Oxford UK

Buteler M, Yossen MB, Alma AM et al (2021) Interaction between Vespula germanica and Apis mellifera in Patagonia Argentina apiaries. Apidologie 52:848-859 
331 Carusela MF, Momo FR, Romanelli L (2009) Competition, predation and coexistence in a three trophic system. Ecol Model 220:2349-2352

333 Chalmandrier L, Hartig F, Laughlin, DC, Lischke H, Pichler M, Stouffer DB, Pellissier L (2021)

334 Linking functional traits and demography to model species-rich communities. Nat Commun $12: 1-9$

Chu C, Kleinhesselink AR, Havstad KM, McClaran MP, Peters DP, Vermeire LT et al (2016) Direct effects dominate responses to climate perturbations in grassland plant communities. Nat Commun 7:1-10

Clapperton BK, Möller H, Sandlant GR (1989) Distribution of social wasps (Hymenoptera: Vespidae) in New Zealand in 1987. N Z J Zool 16:315-323.

Connell JH (1980) Diversity and the coevolution of competitors, or the ghost of competition past.

\section{3} Oikos 35:131-138.

Connor EF, Simberloff D (1983) Interspecific competition and species co-occurrence patterns on islands: null models and the evaluation of evidence. Oikos 41:455-465.

Davis MA (2009) Invasion biology. Oxford University Press, England

DeCesare NJ, Hebblewhite M, Robinson HS, Musiani M (2010) Endangered, apparently: the role of apparent competition in endangered species conservation. Anim Conserv 13:353-362

Delmotte C, Marchal JL (1982) Systematic captures of Vespidae (Hymenoptera) during 1980 in five biotopes of Hesbaye (UTM FS20)[Belgium]. Bull Rech Agron Gembloux 17:39-46

Deng J, Angulo MT, Saavedra S (2021) Generalizing game-changing species across microbial communities. ISME Commun 1:1-8

Donovan B, Howie AME, Schroeder NC (1992) Comparative characteristics of nests of Vespula germanica (F.) and Vespula vulgaris (L.)(Hymenoptera: Vespinae) from Christchurch City, New Zealand. N Z J Zool 19:61-71 
355 Dvorak L, Landolt PJ (2006) Social wasps trapped in the Czech Republic with syrup and 356 fermented fruit and comparison with similar studies (Hymenoptera Vespidae). Bull 357 Insectology 59:115

358 Edelstein-Keshet L (1988) Mathematical models in biology. SIAM, Philadelphia

359 Estay SA, Lima M (2010) Combined effect of ENSO and SAM on the population dynamics of the 360 invasive yellowjacket wasp in central Chile. Popul Ecol 52:289-294

361 Fort H (2018) On predicting species yields in multispecies communities: Quantifying the 362 accuracy of the linear Lotka-Volterra generalized model. Ecol Model 387:154-162

363 Fox BJ, Fox MD, Archer E (1985) Experimental confirmation of competition between two 364 dominant species of Iridomyrmex (Hymenoptera: Formicidae). Aust J Ecol 10:105-110

365 Gamarra JG, Montoya JM, Alonso D, Sole RV (2005) Competition and introduction regime 366 shape exotic bird communities in Hawaii. Biol Invasion 7:297-307

367 Gause GF (1934) Experimental analysis of Vito Volterra's mathematical theory of the struggle for 368 existence. Science 79:16-17.

369

370

371

372

373

374

375

376

377

378

379

Grangier J, Lester PJ (2012) Behavioral plasticity mediates asymmetric competition between invasive wasps and native ants. Commun Integr Biol 5:127-129

Harris RJ, Oliver EH (1993) Prey diets and population densities of the wasps Vespula vulgaris and V. germanica in scrubland-pasture. N Z J Ecol 17:5-12

Harris RJ, Thomas CD, Moller H (1991) The influence of habitat use and foraging on the replacement of one introduced wasp species by another in New Zealand. Ecol Entomol $16: 441-448$

Harris RJ, Moller H, Winterbourn MJ (1994) Competition for honeydew between two social wasps in South Island beech forests, New Zealand. Insectes Soc 41:379-394

Harris RJ (1991) Diet of the wasps Vespula vulgaris and V. germanica in honeydew beech forest of the South Island, New Zealand. N Z J Zool 18:159-170 
Holway DA, Case TJ (2001) Effects of colony-level variation on competitive ability in the invasive Argentine ant. Anim Behav 61:1181-1192

Kabashima JN, Greenberg L, Rust MK, Paine TD (2007) Aggressive interactions between Solenopsis invicta and Linepithema humile (Hymenoptera: Formicidae) under laboratory conditions. J Econ Entomol 100:148-154

Kaplan L, Kendell D, Robertson D, Livdahl T, Khatchikian C (2010) Aedes aegypti and Aedes albopictus in Bermuda: extinction, invasion, invasion and extinction. Biol Invasions $12: 3277-3288$

Leathwick DM (1997) Growth and development of queen colonies of Vespula germanica and $V$. vulgaris. N Z J Zool 24:17-23

Leathwick DM, Godfrey PL, Fordham RA, Potter MA (1999) Comparative growth and seasonality of Vespula germanica (F.) and Vespula vulgaris (L.)(Hymenoptera: Vespidae) colonies in the Manawatu region of New Zealand. N Z J Zool 26:27-38

Lester PJ, Beggs JR (2019) Invasion success and management strategies for social Vespula wasps. Annu Rev Entomol 64:51-71

Looijen RC (1998) Holism and reductionism in biology and ecology: the mutual dependence of higher and lower level research programmes. PhD thesis, University of Groningen

Lotka AJ (1932) Contribution to the mathematical theory of capture: I. Conditions for capture. Proc Natl Acad Sci 18:172-178

MacArthur R, Levins R (1967) The limiting similarity, convergence, and divergence of coexisting species. Am Nat 101:377-385

MacDougall AS, Gilbert B, Levine JM (2009) Plant invasions and the niche. J Ecol 97:609-615 MacIntyre P, Hellstrom J (2015) An evaluation of the costs of pest wasps (Vespula species) in New Zealand. Int Pest Control 57:162-163

Mack RN, Simberloff D, Mark Lonsdale W, Evans H, Clout M, Bazzaz FA (2000) Biotic invasions: causes, epidemiology, global consequences, and control. Ecol Appl 10:689-710 
Mangunacelaya JC, Chiappa E, Toro H, Guerrero P (1986) Observaciones preliminares sobre la alimentación de Vespula germanica en la zona central de Chile (Hymenoptera:Vespidae). Revista chilena de entomología 13:55-58

Masciocchi M, Corley JC (2013) Distribution dispersal and spread of the invasive social wasp (Vespula germanica) in Argentina. Austral Ecol 38:162-168

Masciocchi M, Beggs JR, Carpenter JM, Corley JC (2010). Primer registro de Vespula vulgaris (Hymenoptera: Vespidae) en la Argentina. Rev Soc Entomol Argent 69:267-270

Masciocchi M, Farji-Brener AG, Sackmann P (2010) Competition for food between the exotic wasp Vespula germanica and the native ant assemblage of NW Patagonia: evidence of biotic resistance? Biol Invasions 12:625-631

Masciocchi M, Unelius CR, Buteler M (2019) Foraging niche separation of social wasps in an invaded area: Implications for their management. J Appl Entomol 143:1115-1121

May R, McLean A (2007) Theoretical ecology: principles and applications. Oxford University Press, England

Moller H, Tilley JAV, Plunkett GM, Clapperton BK (1991) Nest sites of common and german wasps (Hymenoptera: Vespidae). N Z J Zool 18:121-125

Momo FR, Capurro AF (2006) Ecología matemática: principios y aplicaciones. Ediciones Cooperativas. Argentina

Neal D (2004) Introduction to population biology. Cambridge University Press, England Parrish MD, Fowler HG (1983) Contrasting foraging related behaviours in two sympatric wasps (Vespula maculifrons and V. germanica). Ecol Entomol 8:185-190

Pereira AJ, Masciocchi M, Bruzzone O, Corley JC (2013) Field preferences of the social wasp Vespula germanica (Hymenoptera: Vespidae) for protein-rich baits. J Insect Behav 26:730739 
430 Pereira AJ, Pirk GI, Corley JC (2016) Foraging behavior interactions between two non-native 431 social wasps, Vespula germanica and V. vulgaris (Hymenoptera: Vespidae): implications 432 for invasion success? J Insect Sci 16:1-6

433 Pusceddu M, Mura A, Floris I, Satta A (2018) Feeding strategies and intraspecific competition in 434 German yellowjacket (Vespula germanica). PLoS ONE 13:e0206301

435 Pyšek P, Jarošík V, Hulme PE, Pergl J, Hejda M, Schaffner U et al (2012) A global assessment 436 of invasive plant impacts on resident species, communities and ecosystems: the 437 interaction of impact measures, invading species' traits and environment. Glob Change $438 \quad$ Biol Bioenergy 18:1725-1737

439 R Core Team (2020) R: A language and environment for statistical computing. R Foundation for $440 \quad$ Statistical Computing. Vienna, Austria.

441 Sackmann PD, Rabinovich M, Corley JC (2000) Arthropod prey foraged by the German wasp 442 (Vespula germanica) in NW Patagonia Argentina. N Z Entomol 23:55-59

443 Sandlant GR, Moller H (1989) Abundance of common and german wasps (Hymenoptera:

444 Vespidae) in the honeydew beech forests of New Zealand in 1987. N Z J Zool 16:333-343

445 Simberloff D, Von Holle B (1999) Positive interactions of nonindigenous species: invasional $446 \quad$ meltdown? Biol Invasions 1:21-32

447 Soetaert K, Petzoldt T, Setzer RW (2010) Solving differential equations in R: package deSolve. J $448 \quad$ Stat Softw 33:1-25

449 Solé R, Bascompte J (2012) Self-Organization in Complex Ecosystems. Princeton University $450 \quad$ Press, Princeton, USA

451 Spradbery JP, Richards OW (1973) Wasps: an account of the biology and natural history of 452 solitary and social wasps. University of Washington Press, Seattle, USA

453 Spurr EB (1995) Protein bait preferences of wasps (Vespula vulgaris and V. germanica) at Mt 454 Thomas, Canterbury, New Zealand. N Z J Zool 22:281-289 
455 Takeuchi Y (1996) Global dynamical properties of Lotka-Volterra systems. World Scientific, $456 \quad$ Singapore

457 Tamura J, Ingram J, Martin AM, Burridge CP, Carver S (2021) Contrasting population 458 manipulations reveal resource competition between two large marsupials: bare-nosed wombats and eastern grey kangaroos. Oecologia. https://doi.org/10.1007/s00442-021-

461 462 463 464 465 466 467 468 469

470

471

472

473

474

475

476

477 478 479 04959-y

Tilman D (1982) Resource competition and community structure. Princeton University Press, Princeton, USA

Torre L, Tabares PCC, Momo F, Meyer JF, Sahade R (2017) Climate change effects on Antarctic benthos: a spatially explicit model approach. Clim Change 141:733-746

Vet S, de Buyl S, Faust K, Danckaert J, Gonze D, Gelens L (2018) Bistability in a system of two species interacting through mutualism as well as competition: Chemostat vs. LotkaVolterra equations. PloS ONE 13:e0197462

Vilà M, Espinar JL, Hejda M, Hulme PE, Jarošík V, Maron JL et al (2011) Ecological impacts of invasive alien plants: a meta-analysis of their effects on species, communities and ecosystems. Ecol Lett 14:702-708

Volterra V (1926) Fluctuations in the abundance of a species considered mathematically. Nature $118: 558-560$

Wangersky PJ (1978) Lotka-Volterra population models. Annu Rev Ecol Evol Syst 9:189-218

Warren RJ, Reed K, Mathew A, Krupp K, Goodman M, Archibald K et al (2019) Release from intraspecific competition promotes dominance of a non-native invader. Biol Invasions 21:895-909

Wickham H (2016) ggplot2: Elegant Graphics for Data Analysis. Springer-Verlag, New York Willink A (1980) Sobre la presencia de Vespula germanica (Fabricius) en la Argentina (Hymenoptera: Vespidae). Neotropica 26:205-206 
Wilson EE, Holway DA (2010) Multiple mechanisms underlie displacement of solitary Hawaiian Hymenoptera by an invasive social wasp. Ecology 91:3294-3302

482 Wilson WG, Lundberg P, Vazquez DP, Shurin JB, Smith MD, Langford W et al (2003).

483 Biodiversity and species interactions: extending Lotka-Volterra community theory. Ecol

$484 \quad$ Lett 6:944-952

485 Yeruham I, Schwimmer A, Brami Y (2002) Epidemiological and bacteriological aspects of 486 mastitis associated with yellowjacket wasps (Vespula germanica) in a dairy cattle herd. J $487 \quad$ Vet Med 49:461-463 
488 Figures legends

489 Fig. 1

490 Trap design used to capture forage returning to nest (extracted and modified from Harris and

491 Oliver 1993)

492 Fig. 2

493 Average percentage ( \pm standard error) of different arthropods orders in $V$. germanica (blue bars)

494 and $V$. vulgaris (red bars) diets $(N=10$ nests). ** indicates significant differences $(P<0.05)$

495 between wasp species according to the Kruskal-Wallis

496 Fig. 3

497 Lotka-Volterra model prediction of $V$. germanica (blue line) and V. vulgaris (red line) population 498 growth in time (years) based on parameters estimated from the abundances and diets of each 499 species

500 Fig. 4

501 Graphical representation (phase diagram) of competition for preys consumption between $V$. 502 germanica (blue line) and V. vulgaris (red line). Lines represents the specific zero growth rate 503 isoclinas that intersect at positive abundances (equilibrium point; $x=0.85, y=4.83$ ) 
Figures

Fig. 1

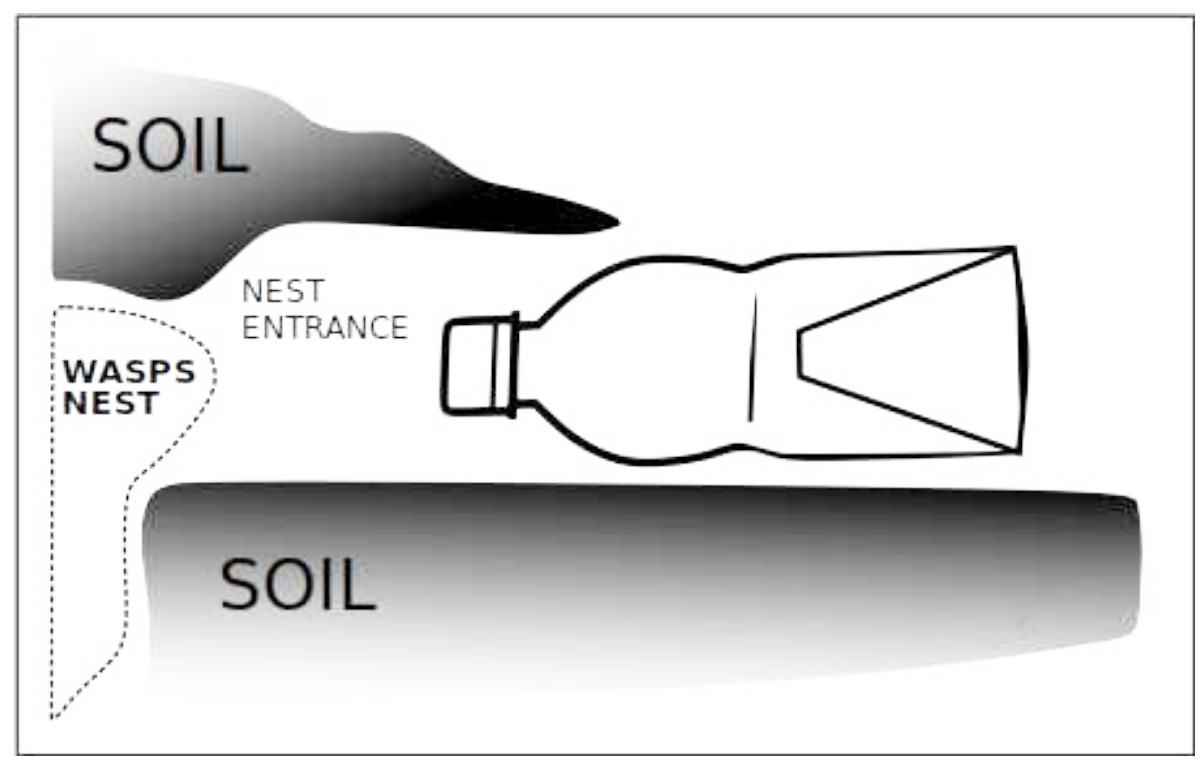


Fig. 2

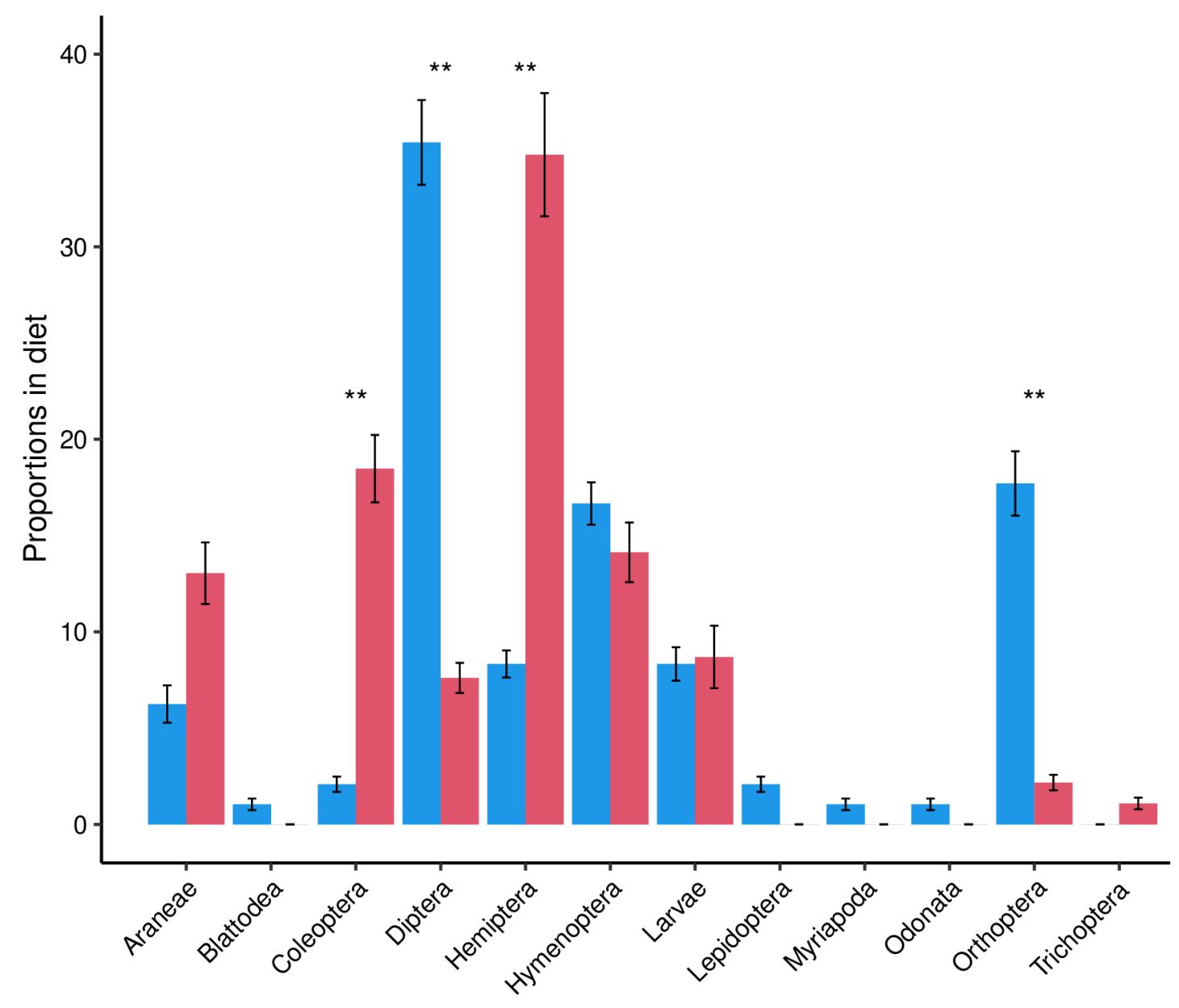


Fig.3

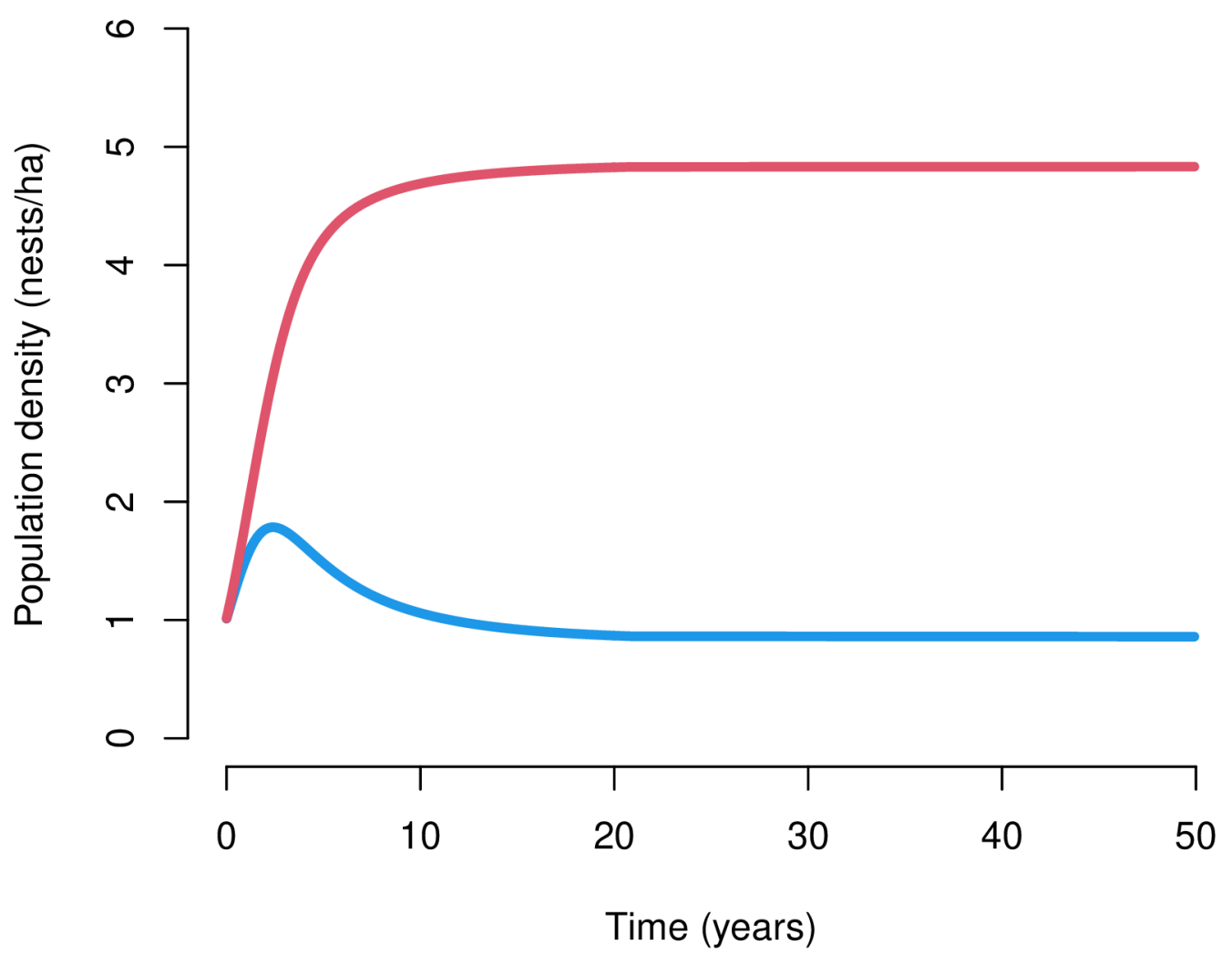


Fig. 4

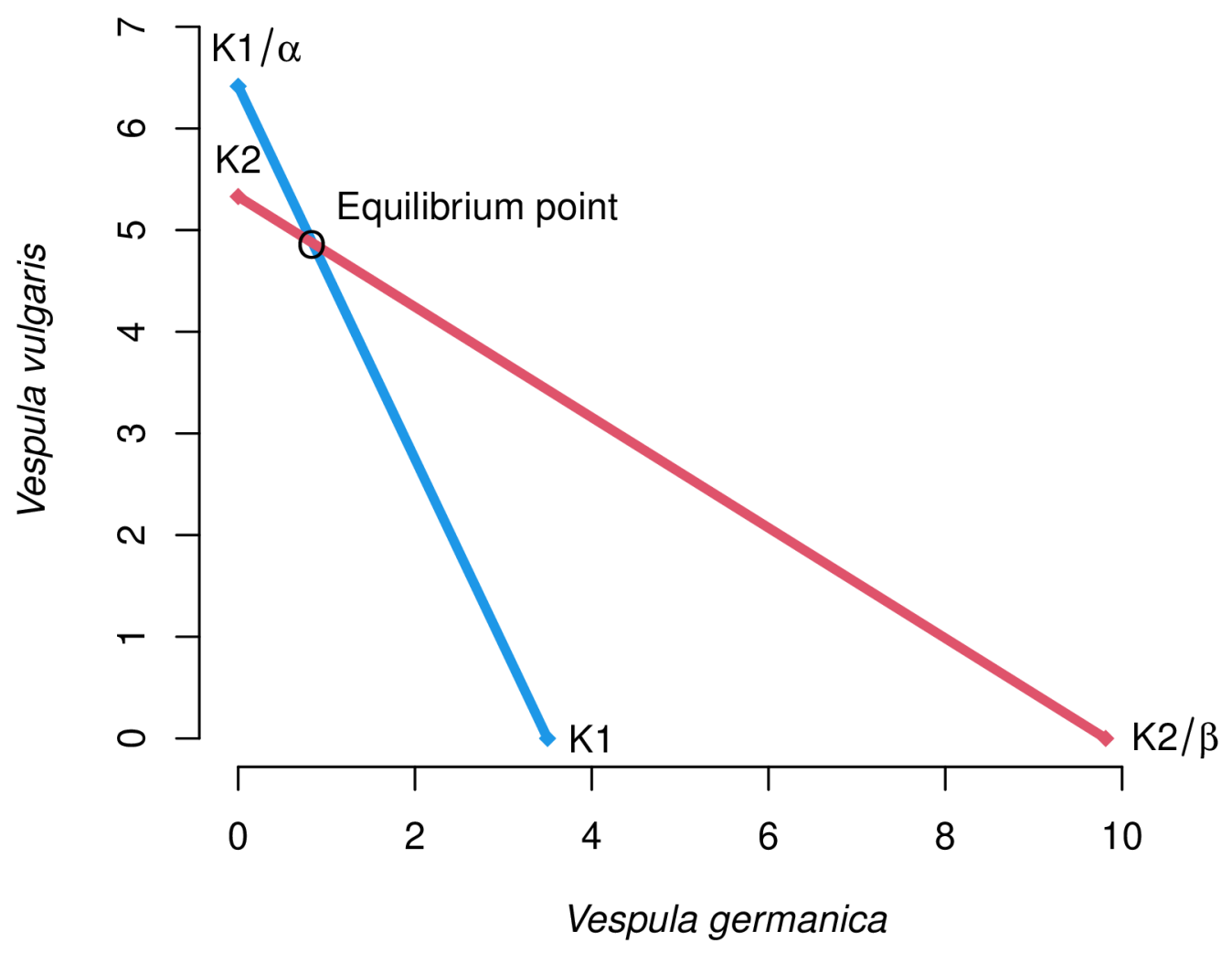

